\title{
Report on the CC:DA Meeting at ALA Annual, June 2019
}

By Donna J. Wells

The Committee on Cataloging: Description and Access (CC:DA) met at the ALA annual conference June 22 and June 24, 2019. The following is a summary of the presentations.

\section{REPORT FROM THE CHAIR}

CC:DA is up for a mandatory 5-year review to continue as an Association for Library Collections \& Technical Services (ALCTS), Cataloging and Metadata Management Section (CaMMS) committee. The submitted report explains the reason for the committee and its ongoing work to demonstrate its value as a committee to the greater ALCTS body.

Also, the Chair reported that the chair of the Virtual Participation Task force had resigned so that committee was seeking members and this will obviously delay testing this process.

\section{REPORT FROM LIBRARY OF CONGRESS}

More detailed information is available at https://alcts.ala.org/ccdablog/wp-content/uploads/2019/06/LC-201902.pdf

LC hosted a large pavilion in the vendor area which looked like a replica of their building. Employees staffed the pavilion during assigned 'office hours' to answer questions on their area of expertise. There were also scheduled presentations throughout the conference at the site.

Open houses, special events, and tours were also offered to conference attendees with free shuttles to and from the events.

LC is seeking a $6.8 \%$ budget increase mainly for infrastructure, technological improvements, and developing better patron services.

Approximately $50 \mathrm{LC}$ catalogers are currently participating in BIBFRAME Pilot Phase 2 with the expectation of 60 more, some from overseas, to participate by the end of the fiscal year.

The national governments of the Republic of Macedonia and Swaziland recently changed the names of their countries to North Macedonia and Eswatini, respectively. The Policy, Training, and Cooperative Programs Division (PTCP) undertook projects to update the LC/NAF, LCSH, and LCC to reflect the new country names.

A project is underway to cancel "multiple" subdivisions. Those are the subdivisions such as French [Italian, etc.], and Christianity [Buddhism, etc.]. These strings will now be established individually. The continued existence of a multiple subdivision for a particular topic cannot be assumed. It is therefore imperative that LCSH be searched at all times, in order to determine whether the multiple has been cancelled. Catalogers may remember the multiples Birth control--Religious aspects--Buddhism, [Christianity, etc.] and Birth control--Religious aspects--Baptists, [Catholic Church, etc.], for example. They were cancelled in May and replaced by 20 individual authority records. Because the multiple was cancelled, all headings of the type Birth control--Religious aspects--[religion or Christian denomination] must have an authority record; that is,

Donna Wells is Associate Director and Head of Technical Services at Southeastern Baptist Theological Seminary. She currently serves as the Atla liaison to the CC:DA. 
they must be proposed as needed. PTCP will inform the community of its progress on the project by updating the spreadsheet on the Multiples Cancellation Project website: http://www.loc.gov/aba/cataloging/subject/ multiplescancellationproject.html

\section{REPORT FROM THE NORTH AMERICAN RDA COMMITTEE (NARDAC)}

The committee members made several presentations to ALA members to help explain the new versions of RDA, reviewed and commented on documents from regional RDA committees, and worked in an advisory capacity to RSC (RDA Steering Committee) regarding the 3R (RDA Restructure \& Redesign) project.

\section{REPORT FROM THE PCC (PROGRAM FOR COOPERATIVE CATALOGING)}

Additional information is available at https://alcts.ala.org/ccdablog/wp-content/uploads/2019/06/PCC-2019-2.pdf

Phase I of the limited use of ISBD punctuation in bibliographic records has been implemented. PCC libraries now have the option of omitting terminal periods of descriptive fields. The guidelines are on the PCC website: https://www.loc.gov/aba/pcc/documents/guidelines-terminalperiods.pdf Phase II, allowing PCC libraries to omit punctuation between subfields of descriptive fields, will be implemented after the ALA annual conference.

\section{REPORT FROM THE RDA RESTRUCTURE \& REDESIGN (3R ) TASK FORCE}

This committee has been very busy since Mid-Winter. They began by exploring the beta version of RDA by taking one bibliographic and one authority record and attempting to find the RDA guidelines that justified each part of the descriptions. This exercise sent many far and wide through RDA as the links were explored. Then began a more systematic examination of the beta RDA, beginning with reading and commenting on the Introduction to RDA, Recording methods, and Resource description sections. Participants were encouraged to follow links and then follow links from the links. Since everyone followed different links, they were able to cover a lot of ground through beta RDA. Comments ran the gamut from discovery of typos to high-level discussions. It is evident that all the comments were read and considered, since they all received responses from RSC. It is also evident that many of the comments resulted in beneficial changes to the text and structure of the beta RDA. For example, a major change that appears to have stemmed from a comment from the Task Force was the addition of a guidance chapter on user tasks.

A YouTube channel for RDA information and training is available at https://www.youtube.com/channel/ UCd5pa3AoQIr17wESE9YHenw/

\section{PRESENTATION FROM THE RDA STEERING COMMITTEE (RSC)}

The title of the presentation was “RDA in English is Stable: Now What?” The English test of RDA is finished and the text now goes to translators. There are 3500 files of text. The translation will occur in steps: first the glossary, then headings, boiler plates (repeated phrases), then the remaining text. RDA is currently published in seven languages and the updated version will have nine different translations. The two new languages are Hungarian and Arabic.

Policy statements are currently under review. It is a complex, backstage process.

Some elements of the new RDA have no MARC equivalents.

So much work done, so much more to do. 


\section{PRESENTATION FROM KATE JAMES OF LC ON THE USE OF NON-HUMAN PERSONAGES IN RDA}

RDA will not allow non-human characters as nomen. These include such things as animals as authors, such as Koko (Gorilla) and fictional characters such as Jessica Fletcher (a TV character). These should be a 700 entry instead. New fields will be created to designate specificity, i.e. animal, non-human, etc.

\section{FUTURE WORK AND PLANS OF CC:DA}

Richard Guajardo volunteered to be co-chair of the Virtual Participation Task Force to handle the technical side of the process. He needs a co-chair to set up meetings, do reports, etc.

ALA is in discussion to restructure the annual mid-winter meeting. News will be forthcoming.

A task force was authorized to revise the CC:DA procedures which have not been updated since 2011.

The 3R Task Force will submit a sample of a proposal to RSC to test the proposal process in RDA. No proposal has been submitted to CC:DA for two years since work began on revamping RDA.

A task force was authorized to investigate the possibility of CC:DA implementing training on the use of RDA.

RSC asks that liaisons to the four groups representing the pseudo-elements in RDA solicit help from their organizations to help with their section of RDA. The four pseudo-elements are Law, Music, Religion, and Official Communications. CC:DA would like the Atla cataloging community to help with the Religion section. Volunteers for this committee will be consulted by the RSC on issues relating to religious terms, usage, form, etc. in the new rules. I will be happy to chair, coordinate, and report. If anyone is interested, contact me at dwells@sebts.edu

The next meeting is January 25, 2020 in Philadelphia. 